\title{
Los cristeros y la jerarquía: variaciones sobre un mismo tema
}

\author{
Cristeros and hierarchy: variations \\ of the same topic
}

doi: http://dx.doi.org/10.32870/

espiral.v23i66.4310

\section{Resumen}

Este artículo pretende profundizar en las relaciones que se establecieron entre los exsoldados de Cristo Rey más pugnaces y el grupo pacifista de prelados que asumió la dirección de la Iglesia católica en México poco antes de que se formalizaran los "arreglos" entre el Gobierno constitucional y el Episcopado mexicano. Con los procedimientos propios al análisis de contenido, aplicados a los textos que emitieron tanto los sublevados como los clérigos, antes y después de la lucha armada, se hace el intento de seguir los deslices discursivos que pusieron en juego las autoridades eclesiásticas para faltar a su promesa inicial de que el régimen gubernamental sería derrocado y hacer creer a los excombatientes que a pesar de la derrota obligada, gracias a su rebeldía se había salvado México de caer en las garras del comunismo.

Palabras clave: Cristiada, martirio, derrota, comunismo, Iglesia.

Agustín Vaca

\begin{abstract}
The aim of this article is to explore deep into the relations established between the most recalcitrant soldiers of Jesus Christ and the group of pacifist bishops who assumed the direction of the Mexican Catholic Church just before the concretion of the informal pact of pacification between the Mexican Episcopate and the Mexican government. Applying the procedures of discourse analysis to the texts published by rebels as well as clergy men before and after the civil war, its made an attempt to follow the discursive changes that clerical authorities gradually introduced to convince the cristeros that although they were forced to abandon the arms before overthrowing President Calles, thanks to them Mexico was saved to fall into the claws of a communist regime.
\end{abstract}

Keywords: Cristiada, martyrdom, defeat, communism, Church.

•Profesor-Investigador del INAH-El Colegio de Jalisco._agustinvaca@hotmail.com 


\section{Introducción}

Entre 1926 y 1929, la rebelión católica que en la actualidad se conoce como la Cristiada afectó al territorio nacional, sobre todo a la región centro-occidente. La finalidad que perseguían sus promotores, tanto laicos como clérigos, era derrocar al régimen gubernamental que encabezaba Plutarco Elías Calles, y con esto terminar la era revolucionaria que apenas empezaba a consolidarse.

En la promoción y desarrollo de esta guerra civil jugó un papel importante la noción de martirio que se reactualizó entre las filas rebeldes con el impulso que, en gran medida, le dio un número indeterminado de clérigos. Pero una vez que se hubo obligado a los levantados a deponer las armas, la jerarquía eclesiástica tomó en sus manos la decisión de promover las causas para conceder la dignidad de mártir a aquellos que considerara adecuados y en el momento que estimara oportuno, lo cual provocó algunas transformaciones notables en la opinión y posición de la Iglesia ante el movimiento.

El objeto de este artículo son, pues, estos deslizamientos paulatinos en el significado y sentido que fueron adquiriendo las sucesivas manifestaciones de parecer y actitud que la jerarquía clerical fue mostrando respecto de la rebelión católica, y el efecto que tuvieron tales transformaciones entre los insurgentes.

Para esto, se ha hecho uso de algunas propuestas del análisis de contenido (Ghiglione, et al., 1980; Robin y Angenot, 1985; Fernández Chaves, 2002; Hernández Sampieri, et $a l ., 2008)$ aplicadas a un conjunto de textos historiográficos, documentales y testimoniales que se han ordenado de manera cronológica, con algunos desplazamientos hacia el pasado o al futuro de los hechos. Por eso, el método historiográfico ha parecido el más útil para destacar la línea temporal de los predicados, o prácticas del habla, que 
revelan, además de los cambios en el tema ya mencionados, el funcionamiento del conjunto de ideas que sustenta una institución para ejercer el poder y su influencia sobre sus subordinados. Aquí debe decirse que el empleo de palabras como "discurso", "discursivas" y otras afines se limita a una acepción directamente relacionada con el proceso racional del pensamiento y su expresión, de lo que se dice acerca de algo; por lo tanto, están lejos de la teoría y práctica del análisis del discurso.

\section{El concepto de mártir}

Si bien es cierto que toda causa, religiosa o laica, tiene sus mártires, creyentes fieles a una corriente de pensamiento determinada que están dispuestos a defender aun ante la posibilidad de perder la vida, el término se asocia, por lo común y en la cultura occidental, con el cristianismo. Desde los inicios de esta religión hasta nuestros días, los cristianos, sobre todo los católicos, no han dejado de recordar y de reactualizar, con un fuerte acento de satisfacción autosacrificial, que su Iglesia tiene sus orígenes, fundamento y supervivencia en la sangre de sus mártires, y esta institución es la que mejor ha sabido aprovechar la entereza de aquellos que han preferido la muerte antes que renunciar en público, cualesquiera que sean las coacciones que se ejerzan, a sus creencias.

El valor del martirio experimentó una notable revivificación entre los católicos mexicanos en cuanto empezaron a patentizarse las desavenencias entre estos y los simpatizantes con los cambios que pretendía introducir la Revolución de 1910 en casi todos los ámbitos de la vida pública, incluidas las prácticas religiosas.

Desde finales del siglo XIX hasta el segundo decenio del xx, la Mitra de Guadalajara tuvo el poder de cohesionar a los jaliscienses en torno de las agrupaciones confesionales 
que integraban el movimiento social católico y que garantizaban la estabilidad de las formas de vida social, económica, cultural y política que respondían a los intereses particulares de los propios habitantes del estado. Si bien estas formas de vida sufrieron ciertos descalabros, sobre todo en el aspecto político con la desaparición del Partido Católico Nacional en 1914 (O’Dogherty, 2001), es justo decir que no se interrumpieron del todo ni siquiera con el estallido de la Revolución. Una vez terminado el conflicto armado, volvieron a cierta normalidad, y el movimiento social católico tuvo una vigorosa reaparición después de 1917, pues varios de los artículos ${ }^{1}$ de la nueva Constitución que afectaban sus actividades sociales habían permanecido sin el reglamento correspondiente que permitiera su puesta en vigor.

Sin embargo, en cuanto ocupó la silla presidencial el general Álvaro Obregón en diciembre de 1920, el Gobierno federal "asumió un papel activo en la promoción del sindicalismo, en la preparación del medio rural para la reforma agraria; en hacer posible el renacimiento de la literatura, el arte y la música nacionales, y sobre todo en la creación de un sistema coherente de educación" (Quirk, 1973, p, 115). La validación de los artículos 3, 27 y 123 por parte del presidente Obregón tenía como propósito principal atraerse a las clases trabajadoras para consolidar al régimen revolucionario por medio de las leyes y alejarse de la vía violenta que, aparentemente, había terminado con el asesinato de Venustiano Carranza en 1920.

Empero, para la Iglesia católica esto redundaba en el impedimento del uso de los últimos recursos legales de que disponía para mantener su influencia entre las clases

I. Estos artículos constitucionales eran el 3, 5, 24, 27 y 130, cuyo contenido puede verse en la Constitución Política de los Estados Unidos Mexicanos. No se describen cada uno de ellos, pues las reacciones que provocaron ya han sido analizadas minuciosamente en las distintas obras sobre el conflicto armado entre los católicos y el Estado. Se remite a la más conocida acerca de este asunto: Meyer (1973-1974, tres volúmenes).

\section{4}


populares: la promesa de mejorar el nivel de vida material de los trabajadores, asunto por el que los sindicatos católicos habían trabajado desde finales del siglo XIX, ${ }^{2}$ y la posibilidad de impartir enseñanza.

De manera casi inmediata, empezaron las rivalidades entre los sindicatos laicos que protegía y alentaba el gobierno constitucional, y los que mantenían las posiciones católicas respecto de las relaciones laborales. Muy pronto los primeros ganaron fama de ser socialistas y hasta comunistas, sobre todo según la apreciación de las agrupaciones sindicales que animaba la doctrina social católica.

En esta percepción influyó no sólo la misma Constitución, sino también algunos actos que llevaron a cabo las organizaciones gubernamentales, como el que ocurrió el $1^{\circ}$ de mayo de 1921. Apenas cinco meses después de asumir Álvaro Obregón la Presidencia, los agremiados en los sindicatos laicos en México conmemoraron el Día del Trabajo con un desfile que infundió demasiado entusiasmo a sus integrantes, y al pasar por catedral "algunos [...] subieron al campanario y suplantaron el pendón nacional que ondeaba en aquel lugar por el rojo y negro" (El Informador, 1921, pp. 1 y 8). En Guadalajara sucedió algo similar, y de inmediato, Miguel Gómez Loza, quien más tarde sería gobernador cristero de Jalisco, trepó a lo alto de la torre e hizo girones la insignia, provocando una refriega entre católicos y laicos que no pasó a mayores (Camberos, 1966, p. 68). Esta toma de las cumbres catedralicias por parte del sindicalismo oficial se repitió en otras ciudades más; sin embargo, fue en la de Morelia donde tuvo mayores consecuencias.

2. Aunque en rigor se trataba más bien de asociaciones mutualistas, estas recibieron el nombre de sindicatos, organizaciones cuya creación laica se dio a finales del siglo XIX, pero sobre todo a principios del XX (Ceballos, 199I). 


\section{El discurso del martirio y sus modificaciones}

Debido a que ese primero de mayo había elecciones en Michoacán, la conmemoración del Día del Trabajo se aplazó para el día 8 por la mañana. El incidente, de momento, no pareció suscitar problemas, pero en los días siguientes el malestar de los sacerdotes y fieles católicos que se sintieron ofendidos por las banderas rojinegras que ondearon en las torres de la catedral moreliana se agravó seriamente debido a las rasgaduras que sufrió un lienzo con la imagen de la Virgen de Guadalupe durante la refriega que causó el escalamiento, y convinieron en realizar una manifestación de desagravio que se llevó a cabo el día 12 por la tarde, pese a la prohibición expresa de las autoridades civiles. ${ }^{3}$

Tal desobediencia a las órdenes municipales provocó un violento altercado entre ambos grupos que acabó a balazos, con varios muertos en cada lado combatiente. Entre los que integraban el bando sindicalista se encontraba el líder agrario Isaac Arriaga, quien murió en el encuentro junto con varios hombres más, en tanto que los católicos recogieron al menos cinco cadáveres (Nava, 1999, s/p).

Aquí hay que asentar que entre 1921 y 1926, tanto el Estado, en vías de afianzamiento, como la Iglesia católica, necesitada de retener su influencia social, política y económica, se provocaron mutuamente, pero los sucesos más graves fueron este de Morelia y el ataque a balazos que sufrieron en Guadalajara unos obreros católicos a manos del sindicato de inquilinos, de filiación "roja", el 26 de marzo de 1922, a la salida de unos ejercicios espirituales a los que acudieron con motivo de la cuaresma (El Informador, 1922).

Empero, los acontecimientos de Morelia son los que aquí se subrayan por la importancia que tienen para el tema

3. Es necesario mencionar que el gobernador de Michoacán era el general Francisco José Múgica Velázquez, hombre de izquierda radical. Ideólogo de Lázaro Cárdenas, fue impulsor de la educación socialista y del reparto agrario y del ejido.

\section{6}


aquí tratado. Para el caso, las autoridades eclesiásticas se apresuraron a declarar mártires, extraoficialmente, a los caídos en la reyerta del día 12 . Al día siguiente, el obispo auxiliar, Luis María Martínez, habló desde el púlpito a los congregados en la catedral para explicarles que si bien sólo a la Iglesia competía otorgar la distinción de mártir, ${ }^{4}$ él podía afirmar que quienes habían encontrado la muerte en defensa de sus convicciones religiosas obtendrían dicha recompensa, y afirmaba que esas muertes aseguraban la pervivencia de la Iglesia, pues esta había pasado la prueba suprema hacía veinte siglos, cuando el amor de Jesucristo venció a la muerte mediante el premio de la vida eterna para quienes correspondieran a ese amor, sobre todo para aquellos que por afirmar su amor por él perdieran la vida terrenal. Desde entonces,

[...] salpicada de sangre de mártires está nuestra historia, y nunca faltará entre nosotros el martirio como nunca faltará la Eucaristía [...]. La Iglesia vive de dos principios, de dos sangres: de la sangre de Cristo que se vierte místicamente en el altar, y de la sangre de los mártires que se derrama de manera cruenta sobre la tierra. Ni la misa ni el martirio faltarán jamás en la Iglesia. Estas dos sangres, hermanos míos, o más bien esa sangre, porque la sangre de los mártires forma con la de Cristo una sola sangre; esa sangre única es nuestra esperanza, nuestra dulce, nuestra indestructible esperanza (Martínez, 1956, p. 353).

Es importante remarcar que esta "Oración fúnebre" fue una homilía sin título que se pronunció desde el púlpito cinco años antes de que se dieran los primeros brotes de violencia, en 1926, contra las disposiciones gubernamentales que

4. A pesar de que hubo otros muertos en la parte laica, sólo de Isaac Arriaga se dijo que "su gloriosa muerte, no significa que tiene un eslabón más la cadena de los mártires del proletariado [sino el principio de] un gran cambio social, que será el triunfo del proletariado" (Nava, 1999, s/p). En este caso, el panegírico estuvo a cargo de Luis N. Morones, dirigente de la Confederación Regional Obrera Mexicana (CROM). 
generaron la guerra civil conocida hoy como la Cristiada. En 1956, la revista David la recogió, y con el título de "Oración fúnebre" la publicó para conmemorar el treinta y cinco aniversario de los hechos sangrientos que se han consignado antes. El 29 de agosto de 2011, es decir, cincuenta y cinco años después, el título "Oración fúnebre" con que se publicó en David desapareció de esta pieza oratoria y, con algunos párrafos menos, pero con los nombres de algunos católicos caídos en la refriega, se puso en la página web de Radio Cristiandad, ${ }^{6}$ cuya dirección se consigna a pie de página, bajo el rubro de Sermones para los cristeros.

Es decir, las palabras que Luis María Martínez pronunció en 1921 con el propósito evidente de consolar a los deudos y alabar la entrega de los fallecidos noventa años más tarde las actualizaron los interesados en acrecentar el acervo martirial que contribuyera a probar que los ataques a la religión católica los había iniciado el Gobierno civil desde antes que se desatara la rebelión cristera de 1926; pero además, es un indicio innegable de la apropiación y los cambios de sentido y significado a que han sometido ciertos sectores de la jerarquía los distintos enunciados en torno de la validez histórica de las actividades subversivas de los rebeldes

\footnotetext{
5. Más adelante se habla brevemente de esta revista, su creación y del papel que tuvo en la propagación del conocimiento de la rebelión católica. Durante la guerra cristera, se repartió una hoja suelta con el nombre de David, cuyo objetivo era fomentar la defensa armada. Bajo ese mismo título, en agosto de 1952 se empezó a publicar una revista mensual que se dedicó a dar a conocer los hechos y hazañas de los cristeros. A partir del número veintisiete, de octubre de 1954 , al título de David se le agregó la leyenda de "Revista mensual ilustrada órgano oficial de la Legión de Cristo Rey y Santa María de Guadalupe-Veteranos de la Guardia Nacional (Cristeros)". Hasta el número veintiocho, del 22 de noviembre de 1954, los editores de David empezaron a consignar el número de tomo. Ahí empezaba el tomo II. Los números anteriores sólo consignaban el año, el número y la fecha de edición, de allí las diferencias en la forma de citar esta revista. La edición corrió a cargo de los excombatientes cristeros más pugnaces que se agruparon alrededor de la Liga Nacional Defensora de la Libertad Religiosa, mismos que al término de la lucha armada permanecieron fieles a los directores civiles de la sublevación.

6. Ver: http://radiocristiandad.wordpress.com/20I I/08/29/sermones-para-loscristeros/
} 
para conformar un discurso que pueda presentarse actualmente con cierta homogeneidad acerca del merecimiento de la categoría de mártires y justificar la construcción, en Guadalajara, de un santuario para honrarlos.

Si unificar la sangre de Jesucristo con la de los muertos, casi dos mil años después, en el acto de desagravio a la Virgen de Guadalupe tuvo un gran efecto, de igual importancia resulta que el canónigo Martínez profundizara el encono que ya existía entre los fieles católicos y los adeptos a la Revolución. Estos no eran sino "socialistas [que obedecían] tenebrosas consignas [como querer] sustituir en nuestros templos la santa bandera de la Patria por el exótico pabellón rojo y negro, emblema de odio y de sangre" (Martínez, 1956, p. 350), intentos que se encontraron con una firme repulsa católica; pero las rasgaduras que sufrió la imagen de la Virgen de Guadalupe se consideraron un atentado de tal magnitud que llevó al canónigo a declarar que con esto "el socialismo se suicidó pretendiendo destruir la religión y supo el mundo que para México hay algo que vale más que su bandera, la Virgen de Guadalupe; que tocarla es tocar el alma nacional y que morir por ella es morir por Dios y por la Patria" (Martínez, 1956, p. 350). De ahí que haya bendecido, alabado y, de manera implícita, considerado mártires a los hermanos que "en un solo holocausto ofrecieron su sangre al Dios de los cielos y a la Patria de la tierra" (Martínez, 1956, p. 350).

Con todo, el obispo auxiliar tuvo la prudencia de no anteponer su juicio personal al de la institución que representaba y fue claro al decir que "mientras la Iglesia no pronuncie su fallo inapelable, nosotros tenemos el deber de rogar por las almas de nuestros hermanos, por si todavía necesitan ser purificadas por la oración y por el sacrificio" (Martínez, 1956, p. 354). Empero, esta posición de acato al canon eclesiástico que mostró el prelado, y que de manera implícita reconocía la suficiente pureza de los fallecidos para 
ser admitidos en la gloria celestial, poco a poco se sustituyó con otra postura más decidida y explícita conforme fueron ahondándose las discrepancias entre la Iglesia católica y el Estado respecto de las formas en que debían conducirse algunos asuntos que atañían al conjunto de la sociedad, entre ellos la educación, las relaciones laborales, la propiedad privada y la injerencia que concedía la Constitución al Estado en asuntos que pertenecían al régimen interno de las instituciones religiosas.

Esta conjunción de circunstancias llevó a José Miguel Romero de Solís (2006) a concluir, además de otras cosas, que el enfrentamiento entre las dos instituciones tenía un fundamento más político que religioso. Ni siquiera es necesario decir que por muchos años fueron los motivos puramente religiosos los que prevalecieron en la opinión popular, lo que alentó, casi se puede decir que con toda intención, la Iglesia católica.

No se trata aquí de poner sobre esa institución y sus fieles todo el peso de la responsabilidad de la guerra civil que se escenificó entre 1926 y 1929, pues esto equivaldría a pasar por alto la determinante participación que tuvo el Estado en la génesis del conflicto que culminó en un enfrentamiento armado, sino que se trata más bien de escudriñar con un poco más de profundidad en las prácticas discursivas y actitudes concretas que la Iglesia ha manifestado hacia sus feligreses en general, en este caso hacia los cristeros en particular, y las variaciones que las mismas han tenido con el paso de los años.

Hasta el final de su mandato presidencial, en noviembre de 1924, Álvaro Obregón logró solventar en cierta paz los diferendos que tuvo con las autoridades eclesiásticas, incluida la expulsión de Ernesto Filippi, delegado apostólico en México, en enero de 1923 (Muriá, 1982, p. 374). Sin embargo, desde que Plutarco Elías Calles asumió la Pre- 
sidencia, este se mostró dispuesto a aplicar los preceptos constitucionales con todo el rigor que fuera posible.

Por esas fechas, tanto el Estado mexicano como la jerarquía eclesiástica, los sacerdotes y dirigentes seglares, se encontraban en medio de divisiones internas. Mientras Calles intentaba centralizar el poder civil federal que los poderes gubernamentales estatales mantenían fraccionado, los católicos solamente estaban unidos por su rechazo al nuevo régimen, pero "sus puntos de vista sobre cómo actuar ante el Gobierno revolucionario iba[n] desde la franca disposición a eludir conflictos, si esto era posible, hasta la actitud combativa, capaz de intentar la resistencia armada" (Bailey, 1974, p. 44).

Calles se dio cuenta muy pronto de que una de las fortalezas con las que todavía contaba la Iglesia era la acción social, que a veces lindaba de manera muy poco precisa con la actividad política, por eso decidió delimitarla tanto y tan pronto como fuera posible. Tal restricción tuvo efectos casi inmediatos en Jalisco, donde la acción social católica contaba con un número bien nutrido de adeptos, pero no fue Calles quien se enfrentó a los católicos. El gobernador del estado, José Guadalupe Zuno, era tan anticlerical como Calles, pero tan anticallista como anticlerical, antipatía que lo llevó a adelantarse al presidente (Muriá, 1982, p. 379).

Esta posición que adoptó Zuno aceleró el desenlace de las desavenencias entre la Iglesia y las autoridades gubernamentales, y, ya para enero de 1925, Anacleto González Flores, uno de los principales caudillos del movimiento católico en Jalisco, había publicado un manifiesto en el que anunciaba el principio de un nueva persecución religiosa, y en clara alusión a los inicios del cristianismo aseguraba que "de nuevo se abre el circo para los cristianos, de nuevo se levanta el potro y rugen las fieras hambrientas en busca de sangre de mártires y el César quiere solazarse con el 
martirio de la libertad de conciencia [...]" (Rius Facius, 1966, pp. 321-322).

Para evitar esto, González Flores exhortaba a los católicos a unir fuerzas como había sucedido en 1918, cuando, mediante un boicot económico que él mismo dirigió, se logró que el Gobierno estatal derogara los decretos por los que se proponía aplicar el artículo 130 constitucional y limitar el número de sacerdotes que podían ejercer su ministerio en Jalisco (Muriá, 1982, pp. 363-365). Sin embargo, todos los intentos que hicieron tanto las autoridades civiles como las partes eclesiásticas para evitar la guerra fueron infructuosos debido a la intransigencia de uno y otro lado. ${ }^{7}$ Como el desarrollo de la guerra cristera ha sido tratado en extenso y con bastante profundidad en obras de apreciable valor tanto historiográfico como sociológico, no se tratará aquí de esto.

Lo que sí interesa destacar es que desde los primeros indicios de que el camino de las armas era inevitable, la división en el Episcopado mexicano entre los belicistas y los pacifistas se ahondó, y aunque estos eran más numerosos que los primeros, la balanza se inclinó por fin hacia los que impulsaban la rebelión armada, pero, por otra parte, también los católicos organizados en diversas asociaciones, como la Asociación Católica de la Juventud Mexicana (ACJM), la Unión Popular (UP), pero sobre todo la Liga Nacional Defensora de la Libertad Religiosa (LNDLR), favorecían el recurso a las armas para devolver a la Iglesia

7. Pocos autores que se han dedicado al análisis de la guerra cristera disienten de esto. Véanse: José María Muriá (1982), Alicia Olivera (1966), Jean Meyer (19731974), Robert Quirk (1974), David Bailey (1973), Francisco Barbosa (1988), Fernando González (200I), Matthew Buttler (2004), entre muchos más.

8. Estas fueron las organizaciones más visibles en la rebelión católica. Desde su fundación, en 1925, la LNDLR proclamó el uso de las armas y se arrogó el mando supremo de la rebelión cristera, para lo cual contó con el apoyo decidido de los integrantes de la ACJM. La UP intentó permanecer al margen de la guerra y practicar la resistencia civil, pero el curso de los acontecimientos convenció finalmente a Anacleto González Flores de poner su organización bajo el mando de la LNDLR, aunque conservó cierta autonomía respecto de esta. 
los derechos que, según ellos, se restringían mediante los artículos constitucionales recién reglamentados. A esto es necesario añadir la propia reacción del pueblo católico que fue organizándose en grupos armados, de manera, puede decirse que, espontánea, en torno de esta misma idea de la necesidad de contestar con acciones bélicas a las dichas restricciones constitucionales que se imponían a las actividades de la Iglesia.

Ahora bien, la espontaneidad del levantamiento católico popular en contra del Gobierno constitucional que encabezaba Plutarco Elías Calles debe verse con cierta precaución. Si bien ha quedado claro que al interior de la Iglesia católica había fuertes desacuerdos relacionados con la aprobación al levantamiento armado, y que la institución no es la única responsable de la urdimbre, promoción y mantenimiento de la Cristiada, también es cierto que se ha establecido la indudable participación, supuestamente personal, de no muy escasos clérigos en el movimiento armado, en el que desempeñaron diversos e importantes papeles, aspecto que González (2001) trata con profundidad.

$\mathrm{Al}$ respecto, se ha pasado por alto que la manera en que los fieles se representaban a los sacerdotes $-\mathrm{y}$ tal vez muchos todavía lo hagan - terminaba por conferir uniformidad de pensamiento y de acción a la Iglesia católica, pues el imaginario popular parecía no hacer distinción alguna entre los sacerdotes, la institución y la religión misma: es decir, todo indica que la mayoría de los católicos concebía un vínculo indisociable entre religión, Iglesia y clerecía, que se traducía en la seguridad de que atacar a los sacerdotes era lo mismo que atacar a la institución y a la religión, identificación que los mismos clérigos se encargaban de reforzar.

Se mencionarán sólo algunos ejemplos de esto. La novela Héctor, que se publicó bajo el seudónimo de Jorge Gram en 1930 y con un pie de imprenta ficticio que la hacía aparecer como hecha en Marpha, Texas, incluye una descripción 
que hizo el presbítero David G. Ramírez, nombre real del autor, del momento que vivía México por esos años, cuando, según él,

[...] [se] distinguían claramente dos elementos: un pueblo entero, laborioso, abnegado, pacífico, bueno, que representaba la fuerza viva y productora en todo lo largo y lo ancho del país, y que sentía su mayor orgullo en declararse sincera y profundamente católico; su anhelo único: cantar a su Dios y a su Virgen de Guadalupe, y trabajar en paz para sus hijos. El otro elemento, una vil minoría ambiciosa y audaz, cruel y asesina, que apoyada en sus bayonetas, ocupaba el poder, fustigaba a la mayoría pacíica, le exprimía con tributos y exacciones y le vilipendiaba por su catolicismo [...]. Para aquella minoría bastarda, el sacerdote era el monstruo más horrendo. Para el pueblo todo, era el personaje más amado (Gram, 1983, p. 65).

Todavía un cuarto de siglo después de terminada la rebelión católica, Víctor Venes Matién ${ }^{9}$ publicó un relato en el que un abuelo cuenta a su nieto las andanzas propias y las del padre del niño en las filas cristeras. Lo que más impresión causa en el niño es que durante esa guerra se haya matado a curas, pues a él "le habían enseñado que los sacerdotes son personas consagradas al servicio de Dios, que sólo se les debe besar la mano con todo respeto, y con el sombrero quitado, como lo hacía él en el pueblo cuando encontraba al señor cura [...] pero matarlos... jeso es inaudito!" (Venes Matién, 1952b, p. 193).

9. Este excombatiente cristero fue uno de los colaboradores más constantes de la revista, y sus textos son bastante significativos para conocer el sentido y los cambios que sufrió el concepto acerca del movimiento de acuerdo con la actitud de la jerarquía hacia este. Su nombre aparece con varias grafías a lo largo de las páginas de David, y puede aparecer como Víctor Verez Matien, Víctor Venez Matién, Víctor Benes Matien o Víctor, a secas, pero se trata de la misma persona. Todo indica que la grafía correcta es Víctor Venes Matién. Por eso, las colaboraciones que de él se citan aquí aparecen con esta grafía.

\section{4}


Aquí es necesario destacar la similitud entre esta concepción que tenían algunos clérigos del pueblo mexicano a principios del siglo Xx, y la que expresaba Juan Sandoval Íñiguez casi un siglo después, en ocasión de la colocación de la primera piedra del Santuario de los Mártires: según el prelado, México seguía siendo "un pueblo creyente y un pueblo de Dios" (Ortiz Aguilar, 2000, p. 12), con lo cual, más que ignorar, desdeñaba los distintos análisis que ya se habían publicado acerca de la diversidad religiosa en Guadalajara (Fortuny, 1999), diversidad que cada vez se extendía más por el país, como han hecho patente De la Torre y Gutiérrez (2007) y Medina (2007), por mencionar sólo algunos trabajos al respecto.

\section{Discurso del triunfo seguro}

Estos relatos que provenían tanto de jerarcas como de curas y pueblo en general mantienen tal coherencia entre sí que dejan ver la plena conciencia de los clérigos del significado y peso que tenían sus palabras y acciones entre sus fieles. Por eso, actitudes como la del cura Narciso Elizondo, quien bendijo a los que se levantaron en armas bajo las órdenes de Victoriano Ramírez, "El catorce”, y Miguel Hernández en San Julián, Jalisco, a finales de 1926, fueron recibidas como la aprobación no sólo de este sacerdote en particular, sino del clero en general de las hostilidades bélicas, y hasta como una bendición divina (Ortiz, 1952, p. 109). Quizá esto adquiera un significado más amplio y nítido con las palabras que al respecto dijo el obispo de Huejutla, Hidalgo, José de Jesús Manríquez y Zárate.

A principios de 1927, justo cuando los brotes bélicos antigubernamentales se diseminaban por el centro-occidente del país, dicho prelado se encontraba en El Paso, Texas, exiliado al igual que otros jerarcas en distintas ciudades del extranjero por su oposición a la Carta Magna de 1917. 
En ese lugar, desde el púlpito, el obispo alabó la decisión de los católicos de levantarse en armas y

[...] proclamar a Cristo en los campos de batalla en pleno siglo $X X$ [con lo cual] ha[n] defendido vigorosamente, no sólo con plegarias, no sólo con desagravios, sino derramando torrentes de sangre generosa [derramamiento que lo lleva a asegurar que] el pueblo mexicano triunfará esta vez en toda la línea, porque su causa es la causa de la verdad y la justicia, es la causa de Jesucristo [...]. Él puede en un momento, con su planta divina derribar ejércitos y hollar todos los enemigos de Dios [...]. Y ya empieza a hacerlo (Manríquez y Zárate, 1952, p. 93).

Este trozo de la alocución que Manríquez y Zárate dirigió a los primeros rebeldes se acerca más a la arenga que al sermón. No sólo los anima a llevar la guerra hasta el final, sino también les asegura que este no puede ser otro sino el triunfo católico sobre el régimen gubernamental. Pero además, la alusión a la sangre derramada por convicciones religiosas de inmediato remite a la homilía que en 1921 pronunció Luis María Martínez en Morelia y que parece un anticipo de las promesas que, cinco años después, varios curas hicieron a los hombres y las mujeres que combatieron por Cristo Rey: serían mártires y tendrían la gloria celestial asegurada por el solo hecho de morir durante las maniobras bélicas. ${ }^{10}$

De allí que desde los inicios de la lucha cristera se hayan conformado dos discursos coetáneos y casi indisociables uno del otro: el del derrocamiento absoluto del régimen constitucional mediante el favor divino, y el del mártir inmediato, que tenía como premio la admisión en el paraíso para los combatientes que murieran en el campo de batalla. El 15

10. En las páginas de David abundan los casos de hombres y mujeres que abrazaron la causa cristera debido a esta promesa, al igual que los de madres y esposas que alientan a hijos y maridos a rebelarse únicamente en pos de ganar la gloria eterna. El mismo motivo actuó poderosamente en las militantes de las Brigadas Femeninas de Santa Juana de Arco (Vaca, 1998).

\section{6}


de agosto de 1927 -día de la Asunción de María, cuyo papel como intermediara ante Dios a favor de la redención y salvación humana es bien conocido-, desde la clandestinidad que había asumido a partir de mediados de 1926, Francisco Orozco y Jiménez expidió la XVII Carta pastoral, en la que destacaba

[...] el valor heroico con que han sufrido el martirio, no ya uno o dos entre el venerable clero y los fieles, sino una ya verdadera pléyade de ínclitos confesores de Cristo [...]. Consignaré aquí algunos, que la voz pública ya preconiza [...] el buen padre David Galván de Guadalajara, señor cura Batis, de Durango, varios jóvenes de la benemérita Asociación de la Juventud Mexicana. Mi amada esposa la Iglesia de Guadalajara ciñe su frente con los nombres imperecederos de siete denodados sacerdotes: don Jenaro Sánchez, colgado y apuñalado; señor cura de Nochistlán don Ramón Adame ajusticiado cruel y villanamente; don Sabás Reyes, héroe con nota de crueldad neroniana, sacrificado en Tototlán; señor cura de Tecolotlán, don José María Robles Hurtado cruelmente sacrificado en una montaña; el respetabilísimo y benemérito señor cura de Totatiche don Cristóbal Magallanes, acompañado del novel y ejemplar sacerdote don Agustín Caloca, fusilados en Colotlán; el humilde y abnegado sacerdote don José Isabel Flores, vicario de Matatlán que sufrió con toda heroicidad [...]. Los nombres de Anacleto González Flores, Luis Padilla, Jorge y Ramón Vargas, hermanos, y Ezequiel y Salvador Huerta, también hermanos, son bien conocidos con todos los detalles de su heroico fin [...]. Al hablar de esta manera, no por esto quiero adelantarme al juicio elevado y respetabilísimo de la Santa Sede, a quien corresponde dictaminar, discernir y aquilatar los méritos de las víctimas enumeradas [...]. Yo me concreto a consignar aquí, para edificación y estímulo vuestro, el concepto favorable en que ya tiene en su memoria la pública estimación de los fieles [...] (Orozco y Jiménez, 1927). "'

II. Con excepción del sacerdote David Galván, que fue fusilado en 1914, todos los demás que se mencionan en esta carta pastoral murieron durante la rebelión cristera. 
Toda proporción guardada entre las personas, las condiciones y la posición ante el conflicto armado, el arzobispo tapatío observó el mismo respeto por las leyes canónicas que seis años antes había expresado Luis María Martínez en Morelia, pero, en medio de las circunstancias que iba imponiendo el desarrollo de la guerra civil, Orozco y Jiménez mostró un firme respaldo a los sublevados y resumió la opinión pública para fortificarla e impulsar el deber de los católicos de por lo menos reverenciar la conducta ejemplar de los combatientes por Cristo Rey, sus confesores y guías espirituales en aras de la salvación eterna.

Mientras a principios de 1927 se propagaba la guerra por gran parte de la región centro-occidental del país, y al mismo tiempo que algunos clérigos prometían el triunfo absoluto a los rebeldes, los dirigentes de la LNDLR (Vaca, 1998 , p. 141) ya habían recibido ciertos rumores que los hacían temer un acuerdo entre las autoridades civiles y el grupo pacifista del Episcopado mexicano que pondría fin a la guerra a cambio de la reapertura de las iglesias, aun por encima de los deseos de los sublevados. Sin embargo, no fue sino hasta la segunda mitad de 1928 cuando estos rumores empezaron a tomar visos de realidad.

\section{Discurso del sacrificio necesario}

En junio de ese año, para afirmar su posición ante el conflicto armado, Francisco Orozco y Jiménez, con el respaldo de Leopoldo Lara y Torres, envió un memorial a la Santa Sede en el que, además de oponerse a cualquier forma de convenio pacificador entre el Episcopado y el Gobierno en tanto este no accediera a "la revocación y reformas de las leyes persecutorias" (Orozco y Jiménez, 1962, p. 26), también destacaba que aun cuando la rebelión no alcanzara su meta original, el derrocamiento del "gobierno perseguidor" (Orozco y Jiménez, 1962, p. 26), el movimiento podía ufanarse de la sangre que 
habían derramado los católicos seglares, sacrificio del que aseguró "que si no hubiera habido resistencia armada, los actuales gobernantes jamás se hubieran preocupado de la cuestión religiosa ni de la libertad de conciencia del pueblo mexicano [...] que es el objeto principal de dicha resistencia" (Orozco y Jiménez, 1962, p. 26). Ya no se trataba, pues, de liberar definitivamente a la Iglesia del yugo gubernamental mediante las armas, sino sólo de llamar la atención de las autoridades civiles para que se preocuparan por la cuestión religiosa y la libertad de conciencia.

Aunque Orozco y Jiménez haya sido uno de los primeros arzobispos en admitir la imposibilidad de derrocar a Calles, estas declaraciones del purpurado tapatío sentaron las bases, de seguro involuntariamente, para la desviación que sufrió el discurso del triunfo seguro hacia su transformación en el del sacrificio necesario, que iría conformándose a partir de los arreglos, nombre popular que se impuso al convenio de cesar las hostilidades entre las autoridades eclesiásticas y las civiles que se dio a conocer el 21 de junio de 1929.

Aquí es necesario decir que a pesar de que se ha documentado hasta la saciedad que el culto religioso se suspendió en todo el país por orden de la jerarquía, y que los templos cerraron sus puertas porque los párrocos se negaron a entregarlos a una junta de diez vecinos para que se encargaran de administrarlos (Muriá, 1982, p. 382), todavía subsiste en gran parte de la memoria colectiva la certeza de que fue el presidente Calles quien dio la orden de que las dos cosas sucedieran. Por su parte, González (2001, pp. 248 y 249) sostiene que la mayoría de los católicos tiene presente que fue el clero el que suspendió el culto en los templos, pero que "cuando el Gobierno empezó a perseguir a los fieles y a los ministros en las casas en donde se celebraba, y a fusilar sacerdotes [...] fue claro para algunos católicos quién era el que realmente había suspendido el culto público y, además, el privado". 
Comoquiera, este reconocimiento del fracaso parcial de la rebelión católica lo expresó Francisco Orozco y Jiménez en 1928 al aseverar que si bien el movimiento cristero no había logrado su objetivo principal, derrocar al régimen revolucionario y ateo, en cambio tenía el mérito de haber alertado a las autoridades civiles de la magnitud del problema religioso y de la necesidad de la libertad de conciencia para pacificar al país. En suma, el giro discursivo del triunfo seguro de la rebelión católica, acompañado de la subida inmediata al cielo vía el martirio, que prevaleció en los principios de la guerra civil, paulatinamente se convirtió en el del sacrificio necesario: el levantamiento y sus muertos fueron la víctima propiciatoria que evitó mayores perjuicios morales a la nación mexicana.

Por lo menos eso fue lo que dejaron ver los testimonios de muchos de los excombatientes que empezaron a publicarse hasta un cuarto de siglo después debido a la prohibición expresa de la jerarquía de hacer referencia pública, oral o escrita, a la rebelión cristera. En octubre de 1951, según narró Jesús Degollado Guízar, último jefe supremo del movimiento cristero, el exsoldado de Cristo Rey Eligio Cartagena le envió una carta en la que le pedía que organizara los actos pertinentes para conmemorar el veinticinco aniversario del inicio de la epopeya cristera, como ellos mismos llamaban, por lo menos desde 1928, a la sublevación. Según Degollado, esta solicitud "vino a despertarnos de nuestro sueño, vino a reprocharnos con toda justicia nuestro cobarde silencio y a recordarnos la deuda sagrada que eternamente tenemos contraída con nuestros mártires y héroes" (Degollado Guízar, 1952b, p. 271).

Este despertar de los exintegrantes de las tropas cristeras dio nacimiento, como resultado de una propuesta del segundo obispo de Huejutla, Manuel J. Yerena, a una asociación que provisionalmente se llamó Legión de Cristo 
Rey y Santa María de Guadalupe, cuyos principales objetivos fueron

[...] conservar y fomentar el espíritu auténticamente cristero [...], reunir todos los datos y toda la documentación que se refiere a la epopeya, sus antecedentes, sus consecuencias, sus amigos, sus enemigos, sus héroes y mártires [...], promover informaciones canónicas o no canónicas sobre los héroes y mártires y acontecimientos concomitantes (Degollado Guízar, 1952b, p. 275).

En esa misma reunión se sugirió la publicación de "una revista que sirva de lazo de unión entre todos los socios" (Degollado Guízar, 1952b, p. 275). Aunque ya para entonces la LNDLR se había desintegrado, por lo menos de manera oficial, se afirmó que la legión seguiría "los lineamientos de la liga en su modalidad combativa, con las salvedades de la época y de las circunstancias [para que] reivindique el nombre de los cristeros caídos y divulgue la verdad de ese movimiento" (Degollado Guízar, 1952b, p. 275).

Las "salvedades" a que se refiere se dieron a conocer en el primer número de la segunda época de David, que se publicó en agosto de 1952. Lo primero que llama la atención es no tanto la ilustración que acompaña a la cabeza de la revista, sino el contenido del breve texto al pie de ella, en el que se explica que el Cristo de los cristeros no es un "Rey triunfante y lleno de la majestad de su gloria" (David, 1952a, pp. 1 y 2), sino que

Nuestro Cristo es el Cristo abrazando la cruz y coronado de espinas, porque no supimos en nuestra pequeñez liberarlo de las torturas de su pasión [...]. Tenemos que reconocer que nuestro Cristo aún sufre persecución y es escarnecido por la turba desalmada que no sabe comprender las dulzuras de su reino (David, 1952a, Pp. 1-2). 
Por eso pervive en los excombatientes el compromiso moral que habían contraído de "librar a nuestro rey del peso de su cruz y de su corona de espinas" (David, 1952a, pp. 1-2).

Para que se comprenda el significado de esta declaración, hay que recordar que durante la guerra civil circuló de manera clandestina una hoja suelta de carácter combativo que se llamó David, cuyo propósito era animar a las tropas cristeras a luchar hasta establecer el reinado espiritual y temporal de Cristo; de ahí que en esta segunda época se enfatice que

David no viene ahora, como antaño, empuñando la honda para derribar al gigante, y la espada para cortarle la cabeza [sino que sólo desea] cantar las glorias de Dios y de su madre santísima. Cantando las glorias de sus valientes hijos [se sabrá que fueron] Cristo Rey y santa María de Guadalupe los inspiradores de sus virtudes, de sus sacrificios, de sus heroísmos, de sus martirios [...]. Pero sí viene dispuesto a combatir y rectificar los errores [...] que se han venido divulgando sobre el movimiento cristero [cosa que hará] con la energía que le da el saberse poseedor de la verdad de lo acontecido [lo cual] constituye una de las más gloriosas páginas de la historia, no sólo de México, sino de los pueblos cristianos (David, 1952b, p. 2).

Las declaraciones de los editores del órgano oficial de la flamante organización de los excristeros más combativos no pueden traslucir con mayor claridad la represión del ímpetu rebelde que ya para entonces habían logrado imponer los jerarcas de la Iglesia, y confirma la dirección que imprimieron al discurso sobre la Cristiada y los cristeros para encaminarlo del triunfo seguro hacia el del sacrificio necesario, desplazamiento que se obligó a secundar hasta a los sacerdotes que mayor respaldo dieron al movimiento cristero.

Tres años antes de que empezara a publicarse David, el dominico Mariano Navarro, quien dio todo su apoyo a las 
Brigadas Femeninas de Santa Juana de Arco, sobre todo en ocasión del conflicto de autoridad que tuvieron con la LNDLR (Vaca, 1998, pp. 240-271), pronunció una oración fúnebre en honor de los cristeros durante uno de los actos que se organizaron para conmemorar el veinticinco aniversario del inicio del levantamiento católico, en la que al comparar la diversidad del concepto de libertad social que sostenían corrientes de pensamiento como el comunismo, liberalismo, francmasonería y otras más aseguró que "los cristeros tenían y tienen el verdadero concepto de la libertad social. El concepto cristiano de la libertad social" (Navarro, 1954, pp. 65-69), apoyado en

[...] el testimonio infalible de la Iglesia católica, que siempre ha sostenido y proclamado que el concepto cristiano de la libertad social es exclusivamente el concepto verdadero. Por eso los cristeros se levantaron en armas [...] tenían derecho y se sintieron obligados [ya que] si mi religión y mi patria han de morir, que mueran en mis brazos (Navarro, 1954, Pp. 65-69).

Había quedado muy atrás, pues, el discurso inicial que garantizaba a los levantados el triunfo seguro y la palma del martirio; ahora se exaltaba sólo el hecho de haber luchado para evitar males mayores, como la propagación del comunismo, corriente de pensamiento que, según el obispo Luis María Martínez (1956, p. 350), se había suicidado desde 1921, pero que más de treinta años después seguía vivo y amenazante. Según aseguraba Mariano Navarro (1954), tal peligro se había conjurado gracias a la guerra santa, y era la disipación de esa amenaza la que hacía de la rebelión una epopeya.

En suma, pues, los clérigos que durante los primeros años de la década de los veinte del siglo XX animaron a los católicos a empuñar las armas para derrocar al ateo, según ellos, que estaba al frente de la administración pública, tres 
decenios más tarde exhortaban a los exsoldados de Cristo Rey a aceptar que aunque desde el inicio de la sublevación era evidente la imposibilidad del triunfo sobre Calles además de que ya no se volvió a mencionar la posibilidad de dar a los caídos la dignidad de mártires-, sus sufrimientos y muertes había sido necesarios, pues con ellos evitaron males mayores a la patria.

\section{El discurso de salvación de la patria}

Ya desde el primer número de David en su segunda época, esta amalgama discursiva fue cada vez más frecuente y difícil de disociar. Según Felipe de Jesús Guízar, "los cristeros fuimos a defender los derechos sagrados de Cristo y los de su santa Iglesia, teníamos obligación de defender y no de ganar" (1952, p. 3). En ese mismo número, Víctor Venes Matién, aseguraba que en 1926 "la fiera revolucionaria creyó que había llegado la hora de dar el zarpazo definitivo" (1952a, p. 11), pero "fue entonces que los mansos católicos se convirtieron en leones para defender a la Iglesia y la religión católicas" (Venes Matién, 1952a, p.11); sostenía que si bien la rebelión no tuvo el final esperado, sí logró que "los pecados, las prevaricaciones, el lodo que pudiera tener la historia mexicana, todo parece como purificado por el sacrificio inmenso de los tres años heroicos" (Venes Matién, 1952a, p. 11); y coincidía con Felipe de Jesus Guízar en que si hubo cosas reprobables en los actos de los cristeros, esto sólo lo puede juzgar Dios, "pero visto el conjunto, todo es claridad y nobleza. [por eso] Honor a los que pelearon en aquellos combates. Gloria a quienes murieron por su patria y por su Dios" (Venes Matién, 1952a, p. 11).

El acento, pues, se había desplazado de los méritos personales al valor de la sublevación católica en su conjunto, valor que se fincaba en atribuirle el privilegio de haber redimido a toda la historia de México, por lo menos desde 
el pecado mortal que el país había cometido, según Lucas Alamán (García Cantú, 1986, p. 33), al independizarse de España, pero sobre todo a los pecados que había cometido con la admisión de la reforma liberal cuyos remates fueron la Revolución de 1910 y la Carta Magna de 1917, que afectaban directa e indirectamente a la Iglesia católica y a sus fieles.

A esto mismo se refería Jesús Degollado Guízar (1952a), último general en jefe de la Guardia Nacional, nombre que recibió el ejército cristero, cuando en un artículo empezó por recordar el pasado, no tan remoto, "cuando tus enemigos perseguían tu Iglesia; cuando pretendían arrojarte de tus santuarios [...] México [...] proclamó tu grandeza y te reconoció como rey y señor de su patria [...]" (p. 34), ${ }^{12}$ aunque poco después "cuando la persecución se recrudeció [1926], desterraron a tus representantes, asesinaron o encerraron [...] a muchos de tus hijos [...]" (p. 34); por eso, Degollado Guízar le agradece a Cristo Rey el haber permitido a los católicos valientes formar la LNDLR, la Guardia Nacional y las Brigadas Femeninas, para luchar por revertir ese estado de cosas, pues "cobardes e ingratos hubiéramos sido si no hubiéramos defendido tu legado. Que éramos débiles e impreparados [sic] es una verdad... pero hay derechos que hay que defender aun cuando se tenga la certeza del fracaso [...]" (p. 34).

El mismo Degollado Guízar en otro texto repite casi los mismos argumentos, con lo cual se confirma que ha asumido el giro que se ha dado al discurso acerca de la guerra cristera, desde la seguridad del triunfo con la que se sublevaron, hasta abrazar el discurso del sacrificio necesario por el que admitían que fueron a la lucha a sabiendas de la derrota, pues "la diferencia entre nuestras fuerzas y las del enemigo era enorme; nuestra derrota era casi segura.

12. Se refiere a la entronización de Cristo que se llevó a cabo en junio de 19|4. 
Pero hay derechos que hay que defenderlos aun cuando se lleve la seguridad de perder" (1953, p. 123).

Empero, no todos los jefes cristeros aceptaron con la misma facilidad esta nueva interpretación que se daba a la sublevación católica y sus propósitos. Tal era el caso de Víctor Venes Matién y Aurelio Acevedo, entre muchos de los que en 1929 habían expresado su inconformidad con los arreglos y su incredulidad ante el cambio en la actitud de los obispos que tan valerosos se habían mostrado al inicio del levantamiento, y que al final habían salido "con una y un pedazo"13 (Venes Matién, 1954, p. 12). Venes Matién y Aurelio Acevedo, general brigadier del regimiento Valparaíso durante la guerra y editor de David, expresaron en los artículos que publicaron en esta revista, siempre que tuvieron oportunidad, su convicción en la posibilidad real de que los sublevados habrían derrotado a Calles si los jerarcas no hubieran dado la orden inapelable de alto al fuego (Acevedo, 1954; Venes Matién, 1954), no obstante que la diferencia de fuerzas tan grande entre los soldados de Cristo Rey y el Ejército federal condenaba a los primeros a la derrota segura, como ya se ha dicho que sostenía Degollado Guízar.

Aunque los excristeros habían aceptado el papel de víctima propiciatoria que les ofrecían las autoridades episcopales a cambio de la promesa de que la intervención divina los llevaría al triunfo total, ni los excombatientes ni los clérigos que los apoyaron abandonaron la certeza de haber contado con la fuerza suficiente para derrotar al Ejército federal. En noviembre de 1956, en ocasión de la celebración de la fiesta en honor de Cristo Rey en el cerro del Cubilete, Manuel J. Yerena y Camarena (1957), obispo de Huejutla desde 1940, aseguraba que "la satánica reglamentación de cultos impuesta por el

13. La expresión popular se emplea para referirse a quienes no han cumplido con sus deberes o han faltado a su palabra o traicionado sus ideales y promesas; en este caso se dirige, de manera implícita, a los obispos "arreglistas" Pascual Díaz y Leopoldo Ruiz. 
presidente Calles, incuba[ba] la intención infernal de acabar con el sacerdocio y, por lo mismo, con la Iglesia en México, pues la Iglesia no puede concebirse sin el sacerdocio" (p. 133).

En la misma alocución, el obispo hacía ver que aunque "Calles tenía la fuerza necesaria para que la impía reglamentación prevaleciera a pesar de las protestas del V. episcopado[...] y de los católicos" (Yerena, 1957, p. 133), tres años después de iniciada la guerra "cesaron sus satánicos gritos de victoria" (Yerena, 1957, p. 134) debido al levantamiento católico cuyos integrantes "fueron instrumentos extraordinariamente providenciales" (Yerena, 1957, p. 134), pues si no derrotaron a Calles fue porque "el papá le dijo al hijo [cuando este garbeaba] quítate el sombrero" (Yerena, 1957, p. 134), ${ }^{14}$ por eso

[...] todo católico debería hablar con veneración del ideal cristero;

y reconocer que a la gesta cristera debemos que aún exista la patria de santa María de Guadalupe [...], pues [...] sin sacerdotes no puede existir la Iglesia y sin ella México jamás podrá ser la patria forjada por la Virgen de Guadalupe (Yerena, 1957, p. 134).

A esto se debe que nunca hayan abandonado la certeza de haber participado en una epopeya, y aunque hubiera sido una heroica epopeya suicida, esta era necesaria para salvaguardar la ortodoxia católica del país, como la consideraba Luis Rivero del Val (1970, p. 230).

Pese a todos los esfuerzos que hicieron algunos miembros del Episcopado por dar a la rebelión cristera un objetivo que compensara haber impedido el cumplimiento del inicial, no pudo mantenerse oculta la frustración general

14. Aunque parezca ocioso, ayudaría comprender esta metáfora que utiliza el obispo Yerena. El papá es el Episcopado, el hijo son los levantados que garbeaban, es decir, que tenían superioridad sobre el Ejército federal, pero a los cuales el papá Episcopado les ordenó que se quitaran el sombrero ante el Ejército federal en señal de sumisión. 
que generó la seguridad de que se había luchado en vano, pues "vino ese armisticio que aún nos duele en el alma y nuestra gloriosa bandera fue guardada con cariño, sí, pero guardada al fin" (Téllez, 1955, pp. 108 y 110). Este mismo orador rindió honores a esa bandera que representaba a la trinidad: "Dios, patria y libertad [...]. Bandera que cuando ya la bestia roja había hecho cotidiano el delito, el robo, el incendio y la matanza [fue] levantada por la Liga Nacional Defensora de la Libertad y por su hija legítima, la gloriosa Guardia Nacional" (Téllez, 1955, p. 108), pero, a pesar de haberse visto obligados a guardar la bandera, decían:

[...] debemos regresar a nuestras casas prometiendo solemnemente continuar defendiéndola, porque hoy como ayer, esa bandera santa está en peligro nuevamente y su enemigo es el comunismo ateo y anticristiano [al cual] debemos combatirlo, no porque ahora esté de moda combatirlo o fingir que se le combate porque así conviene a la política allende el Bravo, sino porque el comunismo constituye una amenaza no sólo para México, sino para el mundo entero (Téllez, 1955, p. II0).

Es evidente que Jorge Téllez, en las líneas citadas, se refería a los años desde finales de los cuarenta hasta mediados de los cincuenta, que se significaron por la persecución que el senador Joseph McCarthy desató en contra de los comunistas en los Estados Unidos, a lo cual se sumó el triunfo de la Revolución cubana para crear un clima internacional de anticomunismo, pero además los conflictos sociales domésticos, como la huelga de los ferrocarrileros, en 1958, y otros más que le siguieron que causaron turbulencia social en el país hasta la primera mitad del decenio siguiente, todos los cuales parecieron confirmar los temores de la amenaza comunista que manifestaron tanto la Iglesia como el Estado mexicano (Blancarte, 1992, pp. 178 y ss.).

Ya para terminar, resulta necesario traer a colación un punto en el que la mayoría de los especialistas en los distintos 
aspectos de la guerra cristera han coincidido: la sorpresa que causó a la jerarquía, al igual que a las autoridades civiles, la violencia y rapidez con que se propagó el movimiento cristero y la capacidad de los insumisos para mantenerlo activo (Meyer, 1973; Bailey, 1973; Romero de Solís, 1992). El Ejército federal, como consecuencia de la guerra de guerrillas, no podía someter a los levantados con la celeridad que había previsto, en tanto que el clero perdió su ascendiente sobre las tropas y los dirigentes civiles de estas, los cuales se habían constituido en defensores de la religión, casi pasando por encima de la autoridad de los sacerdotes, que primero habían alentado la explosión de la insurgencia y después ya no podían controlar a los insurgentes.

Por eso, la jerarquía tuvo que dar marcha atrás y emplear toda su fuerza coercitiva para obligar a los inconformes con la orden de dejar las armas a someterse a su mandato, el cual se acató en medio de manifestaciones de rechazo, y sin que esto quiera decir que los excombatientes hubieran tenido duda alguna de haber peleado por una causa no sólo justa, sino santa, y merecer el reconocimiento de su participación en la epopeya cristera, como ellos mismos llamaban al levantamiento.

De allí la necesidad del clero de adaptar el discurso sobre la Cristiada y los cristeros según las circunstancias del momento. Por una parte, para el Episcopado era vital mantener el pacto de paz entre la Iglesia y el Estado como único medio de conservar la poca libertad de acción que le otorgó el Gobierno civil. Por la otra, estaba obligado a intentar calmar las frustraciones y el descontento de los rebeldes, cosa que logró, de manera muy limitada, al convertirlos en salvadores de la patria contra las garras del comunismo, pues ni este honor pudo borrar la frustración y enojo que causó la suspensión unilateral de la guerra.

Fecha de recepción: 04 de noviembre de 2015

Fecha de aceptación: 14 de febrero de 2016 
Bibliografía
Acevedo, A. (1954). "Dónde y cómo se inició el movimiento cristero. 22 de agosto de 1926, Valparaíso, Zac.”. David, III(25), I-9.

Bailey, D. (1974). ¡Viva Cristo Rey! The Cristero Rebellion and the Church- State Conflict in Mexico. Austin: University of Texas Press.

Barbosa Guzmán, F. (1988). Jalisco desde la Revolución. La Iglesia y el Gobierno civil. Guadalajara: Gobierno del Estado de Jalisco-Universidad de Guadalajara.

Blancarte, R. (1992). Historia de la Iglesia católica en México. México: FCE.

Buttler, M. (2004). Popular Piety and Political Identity in Mexico's Cristero Rebellion: Michoacán, 1927-29. Gran Bretaña: The British Academy-Oxford University Press. Camberos Vizcaíno, V. (1966). Francisco el Grande. México: Jus.

Ceballos Ramírez, M. (199I). El catolicismo social de la Iglesia. Un tercero en discordia Rerum Novarum, la "cuestión social" y la movilización de los católicos mexicanos (I89I191 I). México: El Colegio de México.

David ( 1952a). "El Cristo de los cristeros", I(I), I-2.

David (1952b). "Presentándonos", I(I), 2.

Degollado Guízar, J. (1952a). “A Cristo Rey”. David, I(3), 34. (1952b). "Cómo nació la Legión de Cristo Rey y Santa María de Guadalupe”. David, I(I7), 27I.

(1953). "El que tiene confianza en Dios nunca se ve defraudado. (Provervio) [sic.]”. David, I(8), I 23.

Fernández Chaves, F. (2002). "El análisis de contenido como ayuda metodológica para la investigación". Revista de Ciencias Sociales, (junio). Recuperado de: http://www. redalyc.org/articulo.oa?id= I5309604

Fortuny Loret de Mola, P. (coord.). (1999). Creyentes y creencias en Guadalajara. México: CIESAS-INAH.

García Cantú, G. (1986). El socialismo en México Siglo XIX. México: Era. 
Ghiglione, R., Beauvois, J. L., Chabrol, C., y Trognon, A. Bibliografía (1980). Manuel d'analyse de contenu. Paris: Armand Colin. González, F. M. (200I). Matar y morir por Cristo Rey. Aspectos de la Cristiada. México: IIS, UNAM-Plaza y Valdez.

Gram, J. (1983). Héctor. Novela histórica cristera. México: Jus. Guízar, F. J. (1952). "Por qué fuimos a la lucha”. David, I(I), 3. Hernández Sampieri, R., Fernández Collado, C., y Baptista Lucio, P. (2008). Metodología de la investigación. México: McGraw Hill.

El Informador (2 de mayo de 192I). "Otra vez la bandera roja ondea sobre la Catedral de México", pp. I y 8.

El Informador (27 de marzo de 1922). "Matanza de católicos por los bolshevikis [sic]”, p. I.

Manríquez y Zárate, J. J. (1952). "Levántate, pueblo Mexicano". David, I(6), 9 I-93.

Martínez, L. M. (1956). “Oración fúnebre... Por el M. I. Sr. Canónigo de la Catedral de Morelia... posteriormente Arzobispo Primado de México". David, II(46), 350-354.

Medina González, M. C. (coord.). (2007). Una puerta abierta a la libertad religiosa. (México a quince años de las reformas constitucionales en materia religiosa 1992-2007). México: Secretaría de Gobernación.

Meyer, J. (I973-1974). La Cristiada. México: Siglo XXI.

Muriá, J. M. (dir.). (1982). Historia de Jalisco. Guadalajara: Unidad Editorial.

Nava Hernández, E. (1999). Isaac Arriaga. El humanismo militante. Morelia: Universidad Michoacana San Nicolás de Hidalgo. Recuperado de: http://dieumsnh.qfb. umich.mx/ChicagoAPA/desc/EL\%20HUMANISMO\%20 MILITANTE\%20\%20\%28ISAAC\%20ARRIAGA\%29. pdf\#page=37\&zoom=auto,0, I I I

Navarro, M. (1954). "Los cristeros. Oración fúnebre pronunciada en la Basílica de Guadalupe por el M. R. P. P. G. Fr... O. P... Diciembre I8 de I95 I". David, II(29), 65-69. 
O’Dogherty, L. (200 I). De urnas y sotanas. El Partido Católico Nacional en Jalisco. México: CONACULTA.

Olivera Sedano, A. (1966). Aspectos del conflicto religioso de 1926 a 1929. Sus antecedentes y consecuencias. México: INAH.

Orozco y Jiménez, F. (1927). XVII Carta pastoral. Recuperado de: http://www.oremosjuntos.com/SantoralLatino/ FranciscoOrozcojimenez.html (1962). "El pueblo católico no buscó arreglos. Testimonio de prelados que sí sufrieron la persecución en México". David, vI(I22), 24-27.

Ortiz, J. (1952). "Anécdotas y sucedidos. Lo que vi en la Guardia Nacional (Cristeros)”. David, I(7), 109.

Ortiz Aguilar, C. (8 de octubre de 2000). "Fue puesta ya la primera piedra del Santuario”. Semanario, p. 12.

Quirk, R. (1973). The Mexican Revolution and the Catholic Church 1910-1929. Bloomington: Indiana University Press.

Ramírez, D. G. (1983). Héctor. Novela histórica cristera. México: Jus.

Rius Facius, A. (1966). Méjico cristero. Historia de la ACJM 1925 a 1931. México: Patria.

Rivero del Val, J. (1970). Entre las patas de los caballos. México: Jus.

Robin, R., y Angenot, M. (1985). "L'inscription du discours social dans le texte littéraire". Sociocriticism, (I), 53-82.

Romero de Solís, J. M. (2006). El aguijón del espíritu. Historia contemporánea de la Iglesia en México (I 892-1992). México: Instituto Mexicano de Doctrina Social CatólicaArchivo Histórico del Municipio de Colima-Universidad de Colima.

Téllez, J. (1955). "Discurso de clausura de la Primera Convención pronunciado por el señor... el 23 de enero de 1955”. David, II(3I), I08-IIO. 
Vaca, A. ( 1998). Los silencios de la historia: las cristeras. ZapoBibliografía pan: El Colegio de Jalisco.

Venes Matién, V. (1952a). “Agosto de 1926”. David, I(I), II-I 2 .

(I952b). "Vivaqueando”. David, I(I2), 193.

(1954). "¿Licenciamiento o rendición? 'Agosto I5 de 1929 XXV años'. El callismo exigió rendición incondicional para humillar a quien no pudo vencer". David, III(25), I I-I6.

Yerena, M. (1957). “'No fueron inútiles aquella invocación y aquella firmeza'. Síntesis de los conceptos expresados por el E. Sr. Obispo de Huejutla Dr. D. Manuel Yerena, en la festividad cristera celebrada en el Cubilete el día 4 de noviembre de 1956”. David, III(57), I 33 y I 34. 